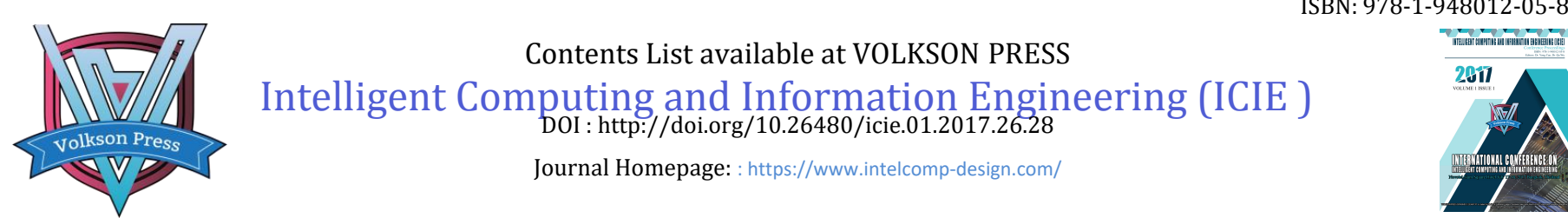

\title{
The Application of TRIZ Theory for Innovative Design Intelligently Scattered Grain Pickup Machine on the Road
}

\author{
Teng Haikun, Liu Xinsheng, Li Lunbin \\ Heihe University Computer and Information Engineering College, Heihe City, 164300 \\ Email: thk_1983@163.com
}

This is an open access article distributed under the Creative Commons Attribution License, which permits unrestricted use, distribution, and reproduction in any medium, provided the original work is properly cited

\section{ARTICLE DETAILS}

\section{Article History:}

Received 12 May2017

Accepted 12 July 2017

Available online 14 September 2017

\section{Keywords:}

TRIZ, Intelligent Control system, Pickup Device, Separated Device, Lifting Device.

\section{ABSTRACT}

Use the TRIZ theory to construct model, establish the core; adopt the method of functional analysis, cause and effect. Finally, summarize and research the scattered grain pickup machine intelligently on the road. This system pick up grain scattered on the road by pickup device, use the single-board microprocessor, sensor, control hydraulic pressure device to achieve the intelligent control between pickup device and ground distance; choose the size, density based on the pickup grain by separated device, and separate the groceries from grains effectively. It will deliver the selective grain into the rock handler by lifting device. Achieving grain collected packaging, lowering the intensity of labor, improving the peasants' grain production, increasing the sources of feeds for animals, reducing irreversible loss in the course of grain transport, fitting the development policy of saving grain in contemporary countries.

\section{PREFACE}

At present, the most parts of province are using large vans to transfer grain, which exists loss problem of transportation, scatters the grain reaching $0.3-0.6$ kilometers largely. Meanwhile, the skins of soybean and corn will throw the ground in the course of grain's (soybean and corn) reap, some soybean reap machines configure recycled device. But, it exists continuous trouble, the problems of soybean's skin need to pack and loss and so on, cause the loss of soybean's skin and the increase of economy [1]. At present, we give up directly or pick up by hand scattered grain on the road partly, which low the operating efficiency and increase the intensity of labor [2,3]. As for as the problems are concerned, the text use TRIZ theory to design a small intelligent scattered pickup separated machine matched with the tractor, improving the efficiency of picking up, lowing the operating intensity, increasing the farmers' benefits $[4,5]$.

\section{THE PRINCIPLE OF WORK}

This system mainly consists in pickup device、screened-separated device、 grain-lifting device, the system structure is figure 1 showed. Firstly, picking up the scattered grain on the ground by pickup device、 using the four-pestle copying mechanism guarantee stable connect between the scattered grain pickup machine and the tractor (power plant), meanwhile, using the single-board microprocessor, sensor, control hydraulic pressure device to achieve the intelligent control, improve the efficiency of machine working, low the intensity of labor. Secondly, separate the groceries from grains effectively by bothside shaking scattered separated device, improve the rate of grain's clearing. Finally, deliver the selective grain into the rock handler by lifting device. Every device is modularity system, simplifying the assembled difficulty, lowering the serviced cost price.

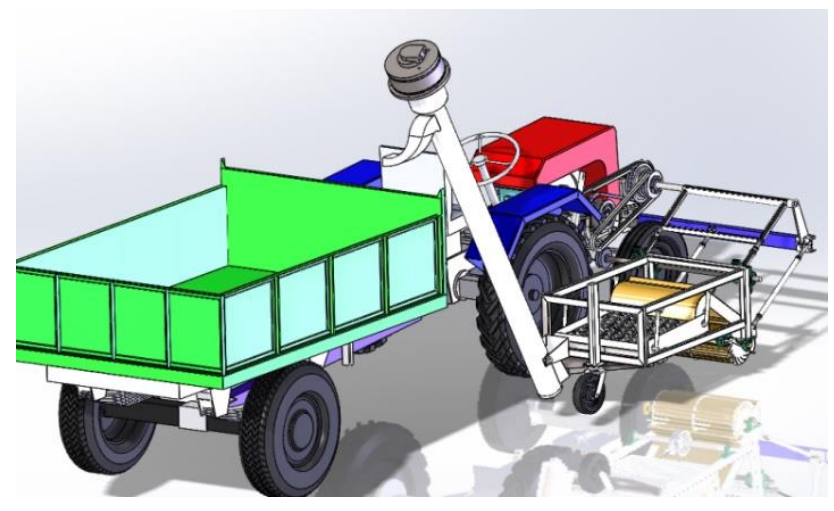

Figure 1: The structure drawing of scattered grain pickup machine

\section{EXISTING PROBLEMS AND LIMITING CONDITIONS}

\subsection{Existing problems}


Pickup device windy blocked: such as some major straw weeds or plastic come into pickup device windy cause windy blocked.

Grain and impurities (soil, stone) separated result: Things picked up are different rely on the weight of grain. For example, the weight of bean is similar to tiny stone, which is not easy to separate by weight. Moreover, if the grain is damaged, it's also difficult to pick up; if the grain on furrows, it's difficult for pickup machine to separate the rest of grain and straw from some soil.

Adjust the height distance from ground based on ground condition and the density of scattered grain. The height varies based on the different degree of density. If the scattered density is large, however, the controlled system's height is short; cover the ground area is small. The machine picked up the scattered grain less than large height from ground, so it's not achieve the goal to pick up the all scattered grain.

\subsection{Limiting conditions}

The products mainly use for smooth highway: The road is crooked in the countryside, so it is very adverse for pickup machine to collect the grain sometimes.

Pickup device's height from the ground and the exhaust opening are failed to control intelligently. It is only control based on the smooth road and the density of grain on the road. The drivers adjust the device based on the road condition.

\section{THE SOLUTION OF USING TRIZ}

\subsection{System analysis}

The context uses the functional analysis based on module components. See figure 2. Firstly, build the module list, describe levels of system composition and each model; secondly, proceeding affect analysis, describing the relationship of each model. Last, establishing the functional model, using the standardization of language to describe [6].

\subsection{Cause and effect analysis}

Depend on the problems of scattered grain pick up on the road, analyze the deep reason caused this result. See chart3 can reach a cause and effect chain analysis.

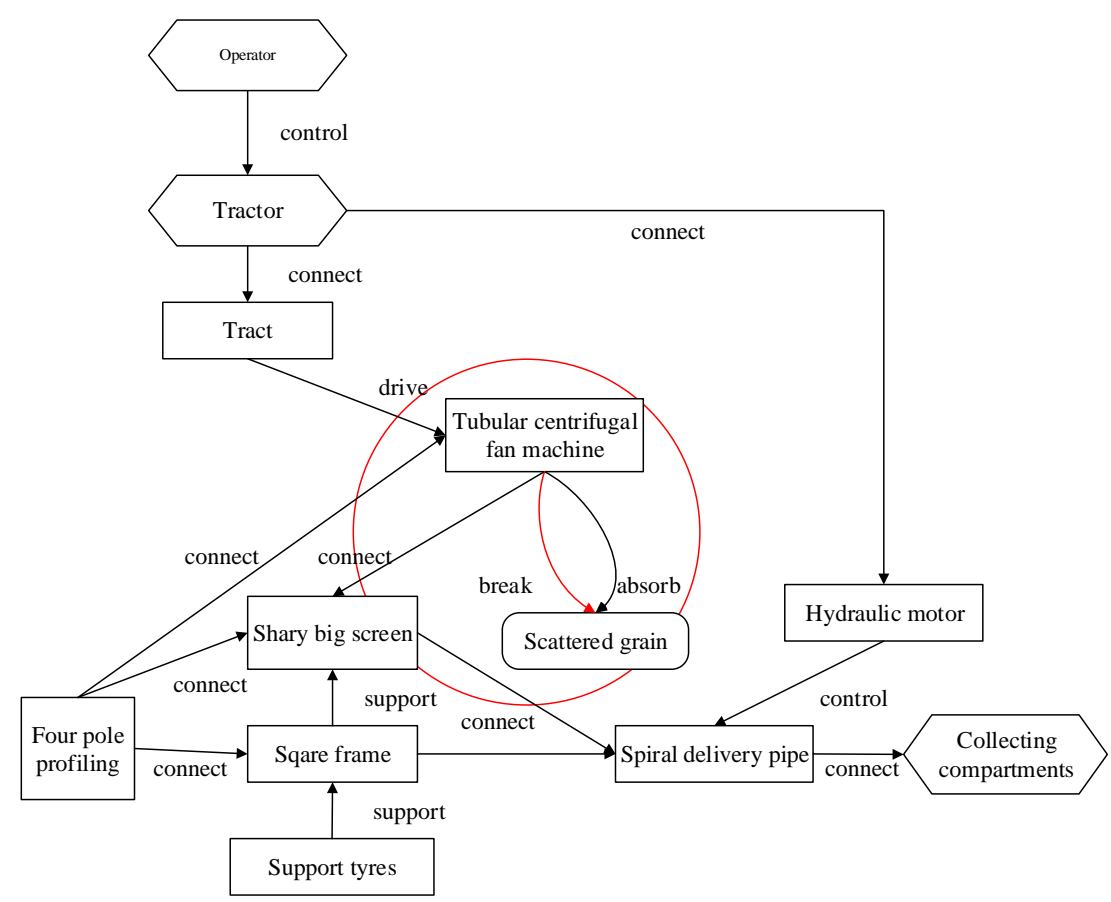

Chart2: The picture of functional model analysis

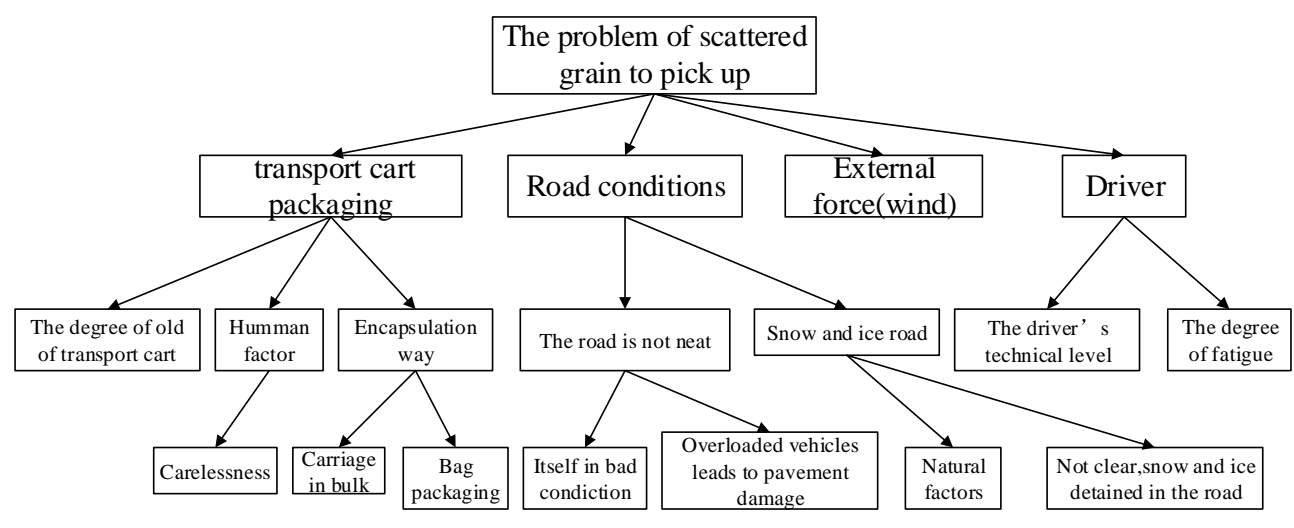

Chart 3: The picture of cause and effect chain analysis

\subsection{Plan production}


Plan 1: Based on the cause-effect chain to analyze, the context use Solidworks application to graphic design scattered grain pickup production (See chart4), use the integration of device of centrifugal fan to realize the grain pickup、multi-grain separation and lifting function. And achieve grain collect effectively. By the products experience found, because of using the centrifugal fan, it makes scattered grain's breakage ratio high and the rate of clearing and picking up low.

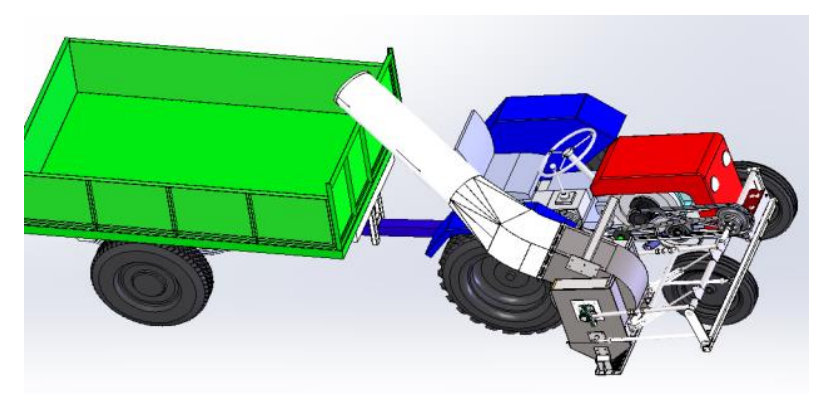

Chart 4: Plan 1 Scattered grain pickup machine schematic diagrams

Plan 2: To analyze the existing problem from plan 1, change this system into model design, use tubular centrifugal fan machine to achieve grain's pickup function. Then use double-plies shaky big screen to separate grain from sundries. The last, use hydraulic motor and spiral delivery to transport cart, see chart5.By experience found, improve the efficiency of picking up grain, reducing grain's breakage ratio, enhancing the rate of clearing.

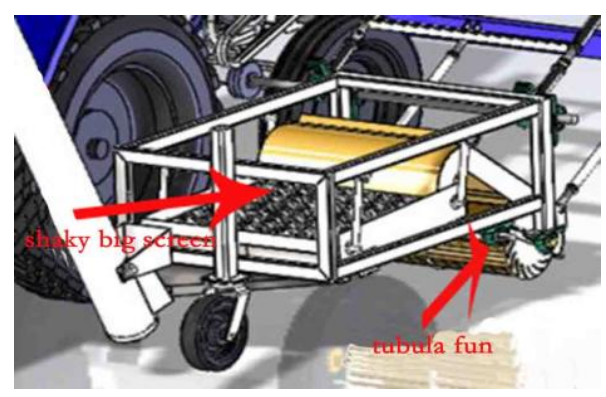

Chart 5: Plan 2 Scattered grain pickup machine improved schematic diagram

\subsection{Programme evaluation and application}

For the concluded technological plan, combine practical product to make sure that use plan 2 into product design and get sample machine in the end, which advances every index from the installation process to pick up grain by the operator practical use. Plans 2 is easy to product and assemble, reduce difficulty of maintenance, improve the rate of grain picking up and clearing, decrease the rate of grain damaged and the congestion of exhaust opening; use hydraulic motor and spiral delivery device to increase the capacity of delivery.

\section{CONCLUSION}

The grain scattered will bring economic loss, consume workers' time and strengthen labors 'intensity. According to existing problems, we design the intelligent scattered grain pickup separated machine in the subject. It is mainly research and experience in structure principle, traditional system, separation device and sensors to identify, which promote scattered grain pickup machine mechanization intelligent development, reduce irreversible loss in the course of grain transport, improve peasants 'economic income, and fit the development policy of saving grain in contem porary countries. Thus, TRIZ theory as an innovation. It plays a significant role in resolving practical question, improving products, researching and developing new products. This article uses the creative thinking method, combine the existing solutions' realistic issue to solve this problem creatively. And create the whole device further. In the end, design a creative、 practical and intelligent design or plan.

Project source: Heihe University horizontal topic-The research and development of intelligently in scattered grain(fodder) pickup-separated machine

\section{REFERENCE}

[1] Wei country. 2016. The damaged assessment and impairment of countermeasures to China's grain transportation. Grain and oil warehouse science and technology communication, 04 (02).

[2] Yang, C. 2014. Reduce grain post-harvest losses rely on science and technology innovation. China's rural science and technology (07).

[3] Chenglin, Y., Longjian, W. 2014. Grain save less need to build a long-time mechanism [J]. China's food economy, (01).

[4] Liwei, G. 2016. The characteristics of major grain post-harvest losses and save less potential research. Agricultural and engineering newspaper, 12(23).

[5] Yan, L., Wenqiang, L. 2012. Innovation design method. Science press.

[6] Zhifeng, L., Di, H., Yang, G. 2012. The improve design of detachable connection based on TRIZ Theory. Mechanical engineering newspaper, 48(11). 